\title{
The impact that cultural food security has on identity and well-being in the second-generation U.S. American minority college students
}

\author{
Kathrine E. Wright ${ }^{1}$ (D) Julie E. Lucero ${ }^{1,2} \cdot$ Jenanne K. Ferguson ${ }^{3} \cdot$ Michelle L. Granner $^{1} \cdot$ Paul G. Devereux ${ }^{1}$. \\ Jennifer L. Pearson ${ }^{1,4} \cdot$ Eric Crosbie ${ }^{1,5}$
}

Received: 29 June 2020 / Accepted: 25 December 2020 / Published online: 25 January 2021

(C) International Society for Plant Pathology and Springer Nature B.V. 2021

\begin{abstract}
Food contributes to an individual's physical and mental well-being and expresses one's cultural identity through preparation, sharing, and consumption (i.e., foodways). Inadequate access to cultural foods can create cultural stress and affect one's identity and well-being. In particular, second-generation U.S. American student populations may have a higher risk for cultural stress due to being away from family, academic stress, environmental changes, and diminished financial stability to purchase cultural foods. Thus, an exploratory qualitative methodology was used to elicit information about second-generation U.S. Americans' food experiences to identify how cultural foods play a role in individual identity and how individual well-being is influenced by the presence or lack of cultural foods. Sixteen semi-structured interviews were conducted with second-generation American students at the University of Nevada, Reno, who self-identified as a cultural or ethnic minority. A standard thematic analysis was conducted. The authors identified that cultural food security influenced the ability to practice foodways, which tied Second-generation American students to their cultural identities. The absence of foodways led to anxiety and depression among students, amplifying the feelings of identity degradation. Second-generation American students discussed that the ability to practice their foodways improved multiple well-being components and led to feelings of happiness, decreased stress, warmth, better digestion, and a sense of belonging, comfort, and safety. College populations continue to grow and become more diverse, and with the increasing Second-generation American students, it is essential to improve the access and availability of cultural foods to improve their overall well-being. (245/250 words).
\end{abstract}

Keywords Food security $\cdot$ Culture $\cdot$ Identity $\cdot$ Well-being $\cdot$ Foodways

\section{Introduction}

First $^{1}$ and second-generation ${ }^{2}$ Americans have been among the fastest-growing populations in the United States due to the Immigration and Nationality Act of 1965, which abolished race and ethnicity-based quotas and created an immigration

\footnotetext{
${ }^{1}$ First-generation American immigrants are individuals who were born outside the United States (Arbeit et al. 2016).

${ }^{2}$ Individuals who were born in the United States to at least one parent who was foreign-born. The term "first-generation American" is also sometimes used in the literature to describe this same population (Arbeit et al. 2016).
}

Kathrine E. Wright

kathrine.e.wright@gmail.com

1 School of Community Health Sciences, University of Nevada Reno, 1664 N. Virginia Street, Reno, NV 89557, USA

2 Latino Research Center, College of Liberal Arts, University of Nevada Reno, Reno, NV, USA boom (Kammer 2015). In 2018, $14.1 \%$ and $12.3 \%$ of the United States population were first and second-generation Americans, respectively, who are predicted to considerably influence the United States' future population growth (Pew Research Center 2020). The Pew Research Center (2015) reported that if current immigration trends continue, future

3 College of Arts and Sciences, MacEwan University, Edmonton, AB, Canada

4 Bloomberg School of Public Health, Johns Hopkins University, Baltimore, MD, USA

5 Ozmen Institute for Global Studies, University of Nevada Reno, Reno, NV, USA 
immigrants and their children will be responsible for $88 \%$ of the population increase in the United States from 2015 to 2065 (Pew Research Center 2020).

The immigration boom in the United States has also led to an increase in second-generation American university students. The proportion of second-generation American undergraduate students increased by 6\% from 1999 to 2000 to 2011-2012, increasing the university student population's cultural and ethnic diversity across the United States (Arbeit et al. 2016). Among these second-generation American undergraduates, $46 \%$ identified as Hispanic or Latino, 23\% identified as White, $14 \%$ identified as Asian, $10 \%$ identified as Black, and $7 \%$ identified as another race or ethnicity (Arbeit et al. 2016).

The drastic environmental change that occurs with collegial transition often creates stressors for incoming college students (Fisher 1994). In addition to these stressors, secondgeneration Americans face additional barriers while attending colleges, such as acculturation stress, cultural barriers, and discrimination; which have been associated with poorer physical and mental health outcomes (Finch et al. 2001; Finch and Vega 2003; Flores et al. 2008; Lee et al. 2004). Secondgeneration Americans often play a balancing act between their cultural and ethnic identity and their American identity, creating additional stress for students (Schwartz et al. 2010). Having a powerful sense of ethnic identity is positively associated with well-being in various ethnic groups (BurnettZeigler et al. 2013; Daponte and Bade 2000; Phinney et al. 1997; Roberts et al. 1999). Thus, identity maintenance in second-generation American students could improve wellbeing outcomes, especially when navigating collegial transition stress (Outten et al. 2008; Ruiz 1990).

Consuming cultural foods is one method students may use to improve to maintain identity and well-being. The foods one consumes, and the transmission of meal-based rituals passed from one generation to the next, are markers of one's cultural and ethnic identity (Noriza et al. 2012; Steinberg 2012). Preparing, sharing, and consuming cultural foods, otherwise known as foodways, are physical and symbolic acts that bind with an individual's cultural identity, which act as "performative pedagogies of remembering" (Herakova and Cooks 2017, p. 241; Parraga 1990; Peñaloza 1994). Additionally, cultural food consumption is associated with nostalgia, familial memories, and feelings of pleasure, belonging, comfort, and well-being (Coveney and Bunton 2003; Locher et al. 2005; Osella and Osella 2008). Thus, many individuals try to safeguard one's culture through foodways, particularly when transplanted to a culturally different location (Beoku-Betts 1995).

Unfamiliar cultural environments challenge one's traditional foodways and diminish the ability to prepare, share, and consume traditional foods, leading to cultural food insecurity. Power (2008) defined cultural food insecurity as having unreliable access to traditional/country food through traditional harvesting practices. Expanding upon Power's definition, cultural food security exists when there is the availability, access, utilization (i.e., food preparation, sharing, and consumption; foodways), and stability of cultural foods (Alonso et al. 2018). Without these vital identity components, acculturative stress (i.e., losing part of their culture; Gabaccia 2009) and food shock can occur, which can affect the students' identity and well-being negatively (Kim 2001; Lum and de Ferrière le Vayer 2016), by creating feelings of social isolation (Vallianatos and Raine 2008) and the loss of their cultural heritage and identity (Gabaccia 1998). Therefore, second-generation American university students must maintain their cultural and ethnic identity as it has positive effects on well-being and health-related quality of life outcomes (Gray-Little and Hafdahl 2000; Ryff et al. 2003; Tsai et al. 2001; Umaña-Taylor et al. 2002; Utsey et al. 2002).

Unfortunately, food insecurity has become a growing concern in higher education. Students who self-identify as a racial or ethnic minority experience food insecurity at higher rates than their peers (El Zein et al. 2017; Gaines et al. 2014; PayneSturges et al. 2018). Data collected from 2007 to 2009 indicated that $26 \%$ of college and university students surveyed had foreign-born parents (Schwartz et al. 2011). In 2012, $16 \%$ of college students were second-generation Americans (Arbeit et al. 2016). While data on cultural food security is not available, second-generation American students who have traditional and cultural needs may be more likely to experience food insecurity than other college students. This is because they are more likely to be negatively affected by diminished access and availability to food that meets their food needs due to structural barriers.

\subsection{Conceptual framework}

A conceptual framework (shown in Fig. 1) was created to piece together the relationship between cultural food security, foodways, identity, and well-being. The arrows in Fig. 1 represent the theorized relationships between the concepts. Previous research has explored the individual relationships between components in this framework (further highlighted below); however, these components have not been considered holistically to our knowledge. As previously highlighted, food is deeply embedded in culture (Feeley-Harnik 1995; Fieldhouse 1995; Kittler et al. 2011; Mintz and Du Bois 2002). The presence of cultural food security diminishes feelings of stress about where to find foods (Moffat et al. 2017; Sanou et al. 2014). This relationship is indicated as 1B in Fig. 1.

Additionally, cultural food security creates an environment where participants can carry out foodways (i.e., prepare, share, and consume cultural foods) [pathway 1A]. Foodways act as a form of cultural transmission and expression that bind cultural members together and accentuate cultural identity [pathway $2 \mathrm{~A}$ ] (Damman et al. 2008, p. 141; Gabaccia 1998; Noriza et al. 2012; Parraga 1990; Peñaloza 1994; Schermuly and ForbesMewett 2016; Steinberg 2012; Vallianatos and Raine 2008; 


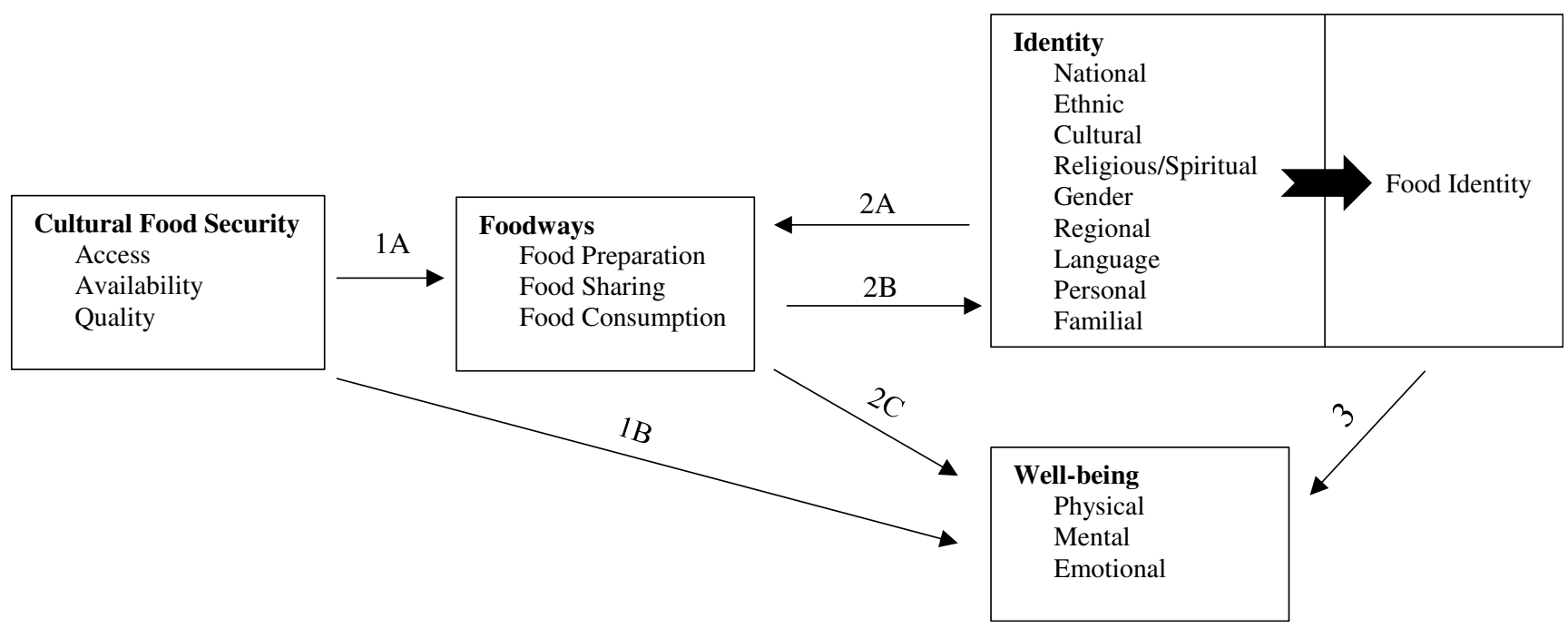

Fig. 1 Conceptual framework theorizing how cultural food security may influence identity and well-being in second-generation American college students

Weller and Turkon 2015), which lead to feelings of happiness [pathway 3] (Damman et al. 2008; Gray-Little and Hafdahl 2000; Ryff et al. 2003; Tsai et al. 2001; Umaña-Taylor et al. 2002; Utsey et al. 2002; Vallianatos and Raine 2008). One's identity can also influence how they prepare, share, consume particular foods [pathway 2B] (Noriza et al. 2012; Steinberg 2012). The act of practicing foodways can bring feelings of comfort and nostalgia [pathway 2C] (Locher et al. 2005; Osella and Osella 2008). However, if foodways are eliminated or strained, the opposite can occur; creating feelings of sadness, stress, and anxiety [pathway 2C] (Trainer et al. 2020), which can lead to feelings of identity loss and disconnection [pathway 3] (Gabaccia 1998; Vallianatos and Raine 2008).

\subsection{Study justification}

Most studies that have examined the effects of identity, acculturation, and well-being in immigrant and international students have been assessed quantitatively and often in one racial or ethnic group (Jung et al. 2007; Schwartz et al. 2013). Schwartz et al. (2013) and Jung et al. (2007) found that immigrant students' culture and identity attachment were associated with well-being. Additional research has examined the importance of food and foodways in immigrants' identity maintenance and well-being (Peñaloza 1994; Rabikowska 2010; Weller and Turkon 2015; Williams-Forson 2014). However, the research examining immigrant's children (i.e., secondgeneration Americans) is lacking. Moreover, most research explores the impact of academic sojourn on culture shock and acculturative stress in international and immigrant students. Academic sojourn is typically defined as a temporary stay in a culturally unfamiliar place for academic study (Brown 2008; Ward et al. 2001). Academic sojourners often are required to cope with substantial cultural changes such as differences in food, language, and cultural norms (Brown and
Holloway 2008), which can lead to acculturative stress and culture shock (Angel et al. 2001; Chang 2009; Liebkind et al. 2004; Sodowsky and Wai Ming Lai 1997). We argue that second-generation Americans can also be academic sojourners as they can move to culturally unfamiliar environments and experience feelings of culture shock and acculturative stress. The United States' demographics can vary drastically from region to region. For example, many of the second-generation Americans were from Las Vegas, Nevada, where 214,283 (32.9\%) residents self-identify as Hispanic/Latino compared to 63,133 (24.7\%) Reno residents (U.S. Census Bureau 2019a, b). American Community Survey data indicated that $61.1 \%$ of Reno's residents identified as non-Hispanic/Latino White, $24.7 \%$ identified as Hispanic, $6.5 \%$ identified as Asian, $4.8 \%$ identified as two or more races/ethnicities, $2.7 \%$ identified as Black alone, $1.1 \%$ identified as Native American or Alaskan Native, $0.8 \%$ identified as Native Hawaiian or other Pacific Islander, and $0.2 \%$ identified as "other" (US Census Bureau 2019b). Lastly, the research linking cultural food security, identity, foodways, and well-being is currently insufficiently explored. This research combines aspects from prior research to examine the relationships between cultural food, identity, and wellbeing in second-generation American college students.

Overall, there is minimal research examining secondgeneration American minority populations. Therefore, this study addresses this gap by capturing qualitative accounts of second-generation Americans cultural food experiences to better understand how (a) cultural food (in)security plays a role in (b) cultural and ethnic identity, to further understand how the relationship between (a) and (b) influences well-being in second-generation American university students, which may differ from the immigrant populations, which have been moderately studied. This study addresses the following research questions: (1) How does cultural food (in)security 
affect cultural and ethnic identity? and (2) how does feeling connected to one's cultural and ethnic identity influence wellbeing? This is the first study, to our knowledge, to explore this relationship in second-generation American students who self-identify as cultural or ethnic minorities.

\section{Materials and methods}

\subsection{Participants}

Sixteen second-generation American undergraduate $(n=13)$ or graduate $(n=3)$ students at the University of Nevada, Reno participated in this study. Initially, participant recruitment was guided by examining similar studies with second-generation college student participants, which have had 5-15 participants (Brady and Stevens 2019; Eaton 2006; Morales 2012; Muñoz 2012; Schackmuth 2012; Skulley 2004). To uphold data saturation principles in qualitative research, the first author concluded the study after 16 interviews as new data did not provide added information (Glaser and Strauss 1967). The purposeful sample included those who self-identified as a cultural or ethnic minority, were 18 years of age or older, believed that food was a critical component of their cultural/ethnic identity (i.e., the believed that they had a non-dominant cultural or ethnic identity), and were students at the University of Nevada, Reno (UNR). Participants born in the U.S. to parents, at least one of whom was born and raised in a country other than the United States, were considered second-generation American. Participants were excluded if they did not meet these criteria. Sixteen out of 39 eligible students agreed to be interviewed for this study under an approved protocol by the university's Institutional Review Board. Five eligible participants removed themselves from the study before the interview. The remaining 18 eligible participants did not respond to six follow-up emails. All participants provided written informed consent before the start of the interview. Tables 1 and 2 provide demographic details for the student sample.

\subsection{Eligibility and recruitment}

The first author posted flyers around campus and sent out emails to multiple UNR academic, student service departments, and student clubs to disseminate study information. Interested students were given a link to a Qualtrics (Qualtrics 2020) screener survey to determine eligibility. Before the start of the screener, survey participants were provided with a consent script. Those who consented were provided access to the eligibility screener survey.

The eligibility screener survey included questions about the student's education level (undergraduate or graduate), how tuition is paid, weekly hours worked, and self-description of their cultural or ethnic identities. The screener also collected
Table 1 Participant Identities

\begin{tabular}{lll}
\hline Pseudonym & Gender & $\begin{array}{l}\text { Self-Identified Cultural } \\
\text { or Ethnic Identity }\end{array}$ \\
\hline $\begin{array}{l}\text { Alice } \\
\text { Jasmine }\end{array}$ & Female & $\begin{array}{l}\text { Mexican } \\
\text { Sarah }\end{array}$ \\
Female & $\begin{array}{l}\text { Filipino and Chinese } \\
\text { Chinese, Korean, Laotian, } \\
\text { and Mexican }\end{array}$ \\
Jennifer & Female & Latina \\
Cloud & Male & Thai and Taiwanese \\
Theresa & Female & Hispanic \\
Joanna & Female & Hispanic/Latina \\
Mary & Female & Filipino \\
Chelsey & Female & Filipino \\
Cyrus & Male & Middle Eastern \\
Sam & Female & Eritrean, African American \\
Fraction & Male & Hispanic/Latino \\
Angel & Male & Latino and Hispanic \\
Aaron & Male & Asian American \\
Jessie & Female & Chinese \\
Daniel & Male & Armenian \\
\hline & &
\end{tabular}

students' demographic information and six-item food security score (US Department of Agriculture 2012).

- Responses of often, sometimes, yes, almost every month, and some months but not every month, were coded as affirmative responses (US Department of Agriculture 2012).

- Total food insecurity scores $0-1$ were interpreted as high food security, 2-4 as low food security, and 5-6 as very low food security based on USDA scoring instructions.

- Cultural food insecurity was assessed by the yes or no response to the question, "Since starting college, have you experienced the inability to purchase the foods that you used to eat at home?"

The answers to these questions are in Tables 1 and 2 . Eligible students were emailed details about the study along with a link to set up an interview time.

\subsection{Interview procedures}

An exploratory research design using qualitative methods was used (Creswell and Creswell 2018). Semi-structured interviews were conducted to elicit information about students' food experiences to identify how cultural foods play a role in one's identity and, further, how one's well-being is influenced by the presence or lack of cultural foods. Interview question topics included defining identity, how food plays a role in identity, memories, cultural foods significance, the experiences and feelings about cultural food loss, and the 
Table 2 Participant Demographics $n=16$

\begin{tabular}{lll}
\hline College Level & $\mathrm{n}$ & $(\%)$ \\
Undergraduate & 13 & $(81.25)$ \\
Graduate & 3 & $(18.75)$ \\
Gender & & \\
Male & 6 & $(37.5)$ \\
Female & 10 & $(62.5)$ \\
Tuition Payment* & & \\
Job(s) & 7 & $(19.4)$ \\
Scholarship or Fellowship & 10 & $(27.8)$ \\
Loans or Grants & 12 & $(33.3)$ \\
Graduate Assistantship & 2 & $(5.6)$ \\
Parents & 5 & $(13.9)$ \\
Weekly Hours Worked & & \\
$0-20$ & 11 & $(68.7)$ \\
$21-40$ & 5 & $(31.3)$ \\
Cultural Food Insecurity (in the last three years) \\
Yes & 9 & \\
No & 7 & $(56.3)$ \\
Food Security Score & & $(43.7)$ \\
High & 7 & \\
Low & 8 & \\
Very Low & 1 & $(50)$ \\
\hline
\end{tabular}

* Participants were able to choose more than one option

influence that foodways have on well-being (Table S1). The semi-structured interviews were conducted by the first author between January 2020-April 2020.

The audio-recorded interviews averaged $70 \mathrm{~min}$. Initially, all 16 interviews were to occur in person; however, due to the COVID-19 pandemic, two interviews occurred over Google Hangouts to protect the participants' and the interviewer's health. E-signatures were obtained for these two participants. Student volunteers who completed CITI (The Collaborative Institutional Training Initiative 2020) human subjects protection training transcribed the interviews verbatim. All data collected in the study were stored anonymously with identifying details removed. During the consent process, participants chose their pseudonyms to enhance anonymity further. To further protect the students' identity, only pseudonyms were used during the recorded interview. Participant pseudonyms and their demographic characteristics are presented in Tables 1 and 2.

\subsection{Qualitative analysis}

The participants' transcripts were analyzed individually, using continuous and abductive thematic analysis (Braun and Clarke 2006) to uncover themes. Thus, the analysis was deductive (a priori themes from the conceptual framework) and inductive (arising from participants' views). During the analytical process, reading the transcribed data occurred multiple times to familiarize the first author with the data. During each reading, comments were written down to highlight key points in the text to identify possible emergent codes. The first author first coded four transcripts in NVivo (QSR International Pty Ltd. 2018) using a priori codes based on the conceptual framework. Emergent codes were identified, discussed with the second author, and then applied to the data. Once patterns in the data arose, the first author reviewed emergent and a priori codes to produce the final codes that were named, defined, discussed in-depth with the second author. Once consensus among the research team was reached, a codebook was developed. Next, all transcripts were coded in NVivo (QSR International Pty Ltd. 2018) using the final code set. These codes were then queried and re-analyzed and then pooled into themes and subthemes. The research team reviewed the coding for validation of coding reliability.

The study findings are organized into three sections that correspond to the conceptual framework found in Fig. 1. Themes uncovered in the analysis are explained within each sub-section and further divided into subthemes, as necessary. Participant quotes are used to support resultant study themes. A list of themes, subthemes, and illustrative quotes are presented in Table 3.

\section{Results}

\subsection{The role of identity in well-being [pathway 3]}

Students mentioned that forgetting their traditional language and losing their cultural identity created feelings of shame and guilt. Daniel mentioned that his identity has been shrinking since he has been away at college and that his cultural identity no longer feels "real," and that he struggles with whom he appears to be on the outside of himself.

I struggle with how I show my culture on the outside. I feel personal guilt. It is something that bothers me. I wish I could do more to uphold my identity. I wish my own performance of my identity felt real. But not speaking my language has really been degrading. I can feel it happening, and there isn't much I can do about it. It's very alone and like isolating...like imposter syndrome. [Daniel]

Jessie also spoke about the impacts of identity loss and the effect it has had on her well-being.

I do feel ashamed when I'm not able to effectively communicate how I feel to my parents, and I'm just forgetting a lot of the Chinese language. So I guess that's where the shame comes from, and it's just hard to bridge that gap sometimes. [Jessie] 
Table 3 Themes and Illustrative Quotes from Second-Generation American Students

\begin{tabular}{|c|c|}
\hline Theme & Example quote \\
\hline \multicolumn{2}{|c|}{ Research Question 1. What is the relationship between cultural food security and identity? } \\
\hline Challenges in achieving cultural food security & $\begin{array}{l}\text { Sometimes I'll eat a lot of other kinds of foods that I'm not used to eating. And I feel like I'm losing my } \\
\text { identity. Like I'm meshing and mixing into another culture and becoming more Americanized. And } \\
\text { it'll be like a lot of fast foods... Being Mexican-Guatemalan-American, I want to eat the food that } \\
\text { comes from the countries that my parents come from. It allows me to connect with them and my } \\
\text { culture more. I feel like now there's just not enough to connect me back there. [Jennifer] }\end{array}$ \\
\hline \multicolumn{2}{|c|}{ Research Question 2. What is the relationship between foodways, identity, and well-being? } \\
\hline Foodways and identity & $\begin{array}{l}\text { It's just one of the things that I bond with my mom a lot. Because even if we're not sitting with family } \\
\text { and having a big meal, I would always help her prep food. She would teach me about how the } \\
\text { flavors should mesh together in a Chinese cuisine. And that's how I learned about how food is } \\
\text { significant in the Chinese culture. I help her a lot in the kitchen, and that's how my mom and I talk to } \\
\text { each other. And she would teach me about her childhood too. Like, 'oh, this is what we ate as kids.' } \\
\text { And it's nothing fancy because they weren't very well off growing up. But, I think it's important to } \\
\text { visualize where my mom came from and her childhood as well. [Jessie] }\end{array}$ \\
\hline Struggles with "Americanization" & $\begin{array}{l}\text { Not eating [my cultural] foods for a very long time changes my identity, where I had to kind of like } \\
\text { adapt to being American. And it's something I don't like. [Angel] }\end{array}$ \\
\hline $\begin{array}{l}\text { Foodways' influences on physical, emotional, } \\
\text { and mental well-being }\end{array}$ & $\begin{array}{l}\text { Sharing foods makes me feel great and wonderful. I don't know where I learned it from, but I always } \\
\text { believed in sharing what makes you happy, right. So for me, food makes me very happy, so I like to } \\
\text { share foods. I feel very happy and very excited to share my foods. Yeah, it is a little bit of warmth. A } \\
\text { very blissful feeling, I guess. It's a little bit of a calming sense of meaning. [Cloud] }\end{array}$ \\
\hline
\end{tabular}

\subsection{The role of Foodways in identity and well-being [pathways 2B and 3]}

Foodways, identity, and well-being are often hard to disentangle from one another. The simple act of carrying out traditional foodways serves as cultural communication, pedagogy, and transmission. Cultural food and foodways are so deeply tied to an individual's identity that a reciprocal relationship is formed [pathways $2 \mathrm{~A}$ and $2 \mathrm{~B}]$. Cultural meal traditions allow students to externalize and construct their cultural and ethnic identity, but their cultural and ethnic identity influences their cultural habits. The upholding of identity through foodways promotes well-being; however, the simple act of preparing, sharing, and consuming cultural foods additionally promotes well-being because of the familiarity and memories tied to the cultural foods [pathway 2C]. Thus, what people eat, how they eat, and whom they eat with reveals the complexity of food and foodways' cultural norms and the cultural policies surrounding foodways. Thus, there is naturally some overlap between the themes, but each describes a unique aspect of the conceptual framework.

\subsubsection{Foodways and identity [pathways $2 \mathrm{~A} \& 2 \mathrm{~B}$ ]}

Foodways (i.e., food preparation, sharing, and consumption) were key components of second-generation American culture and were essential to maintain their sense of cultural or ethnic identity. This is a reciprocal relationship as foodways help form identity, but one's identity also influenced how cultural foods were prepared, shared, and consumed.

Cultural food preparation, sharing, and consumption practices were deeply rooted in their cultural history, which has been generationally passed down. Through these food practices, second-generation American students learned about cultural norms, cultural traditions, cultural history, and connect with and understand their family and ancestors.

It's just one of the things that I bond with my mom a lot. Because even if we're not sitting with family and having a big meal, I would always help her prep food. She would teach me about how the flavors should mesh together in a Chinese cuisine. And that's how I learned about how food is significant in the Chinese culture. I help her a lot in the kitchen, and that's how my mom and I talk to each other. And she would teach me about her childhood too. Like, 'oh, this is what we ate as kids.' And it's nothing fancy because they weren't very well off growing up. But, I think it's important to visualize where my mom came from and her childhood as well. [Jessie]

The students often tied foodways to memories of family. This is critical when second-generation Americans are at college away from their families, as students mentioned that these memories are often the only thing tying them back to their cultural and ethnic identity. 
A lot of my older elders and other relatives, a lot of them still reside in my parents' home countries, Taiwan and Thailand, so whenever I did visit them when I was young, you know, the food is very different and also the typical eating habits are also quite different. So perhaps then I didn't realize, but now that I've grown up, I do appreciate, and I do, think back to just all the love and all the wonderful times and care spent and care given to us from those times. [Alice]

Furthermore, preparing, sharing, and consuming cultural foods embedded students into their social networks that allowed for creating bonds with others through commonalities such as food, music, dance, and language (i.e., culture). Carrying out these practices created a sense of belonging and helped maintain the second-generation Americans' identity, primarily when carried out with other students who shared similar cultural backgrounds. Not only was it essential to have foods that connected students to their family, but it was also essential to connect to others who share similar food memories and food associations among their peers. Other students mentioned that sharing their culture with friends from other cultures helped strengthen their identity and bond with their friends.

I think [sharing cultural foods] definitely makes [my identity] stronger. Whenever I, in general, get to talk about being Eritrean or the history or like the different types offood and how it's prepared and stuff, I feel like it provides my friends with a better understanding of who I am and how I grew up. And like, what my culture looks like. And I think [sharing food] provides us with a stronger bond because it makes them know me much better because they know me that way. [Sam]

Unfortunately, students mentioned that the lack of diversity in Reno's food and population often prevented them from preparing, sharing, consuming their cultural foods, bonding with like identities, and speaking their traditional language with others. Students indicated that losing these experiences made them feel like a significant component of themselves was missing. Joanna expressed this feeling by saying, "not being able to access my culture's foods makes me miss my family the most. I can't really eat them, so I don't have those feelings of comfort or connection. A huge part of me is now missing." Daniel similarly expressed this,

Like there were Armenian restaurants where I used to live as well, so when you would go, you look at the menu, and there might be like the other language listed below the English. I think like my identity feels in a waythe one word to describe it, it's shrinking. I feel less and less Armenian, and like part of me is missing. Like your identity is not there because you don't see anyone like you, no one talks like you, no one eats like you, and no one listens to the music like you. [Daniel]

These findings highlight pathway [1A] in the conceptual framework. Cultural food insecurity led to the inability to prepare, share, and consume cultural foods and secondgeneration Americans felt that this negatively impacted their identity and well-being [pathways 1A, 2B, and 2C].

The relationship between foodways and identity sometimes influenced well-being. For example, cultural food insecurity caused students to adapt to the foods of their unfamiliar environment. When cultural food security (i.e., cultural food access, availability, and quality) existed, second-generation Americans could participate in their cultural foodways and actively partake in their cultural practices. These practices allowed for cultural transmission and food memories that tied them back to cultural members. However, students mentioned that these practices were in danger of being lost because of acculturation and becoming more, as the students said, "Americanized" or losing their cultural or ethnic identity, which, overwhelmingly, produced sadness.

\subsubsection{Struggles with "Americanization"}

One of the most challenging decisions that second-generation Americans had was how much they should adapt to an "American diet" (i.e., non-traditional cultural and ethnic foods). While all the students have U.S. citizenship, many noted that the inability to prepare, share, and consume their cultural foods caused them to become more "Americanized," which was not seen as a positive change. As Angel stated, "not eating [my cultural] foods for a very long time changes my identity, where I had to kind of like adapt to being American. And it's something I don't like." Another student also similarly echoed this,

Sometimes I'll eat a lot of other kinds of foods that I'm not used to eating. And I feel like I'm losing my identity. Like I'm meshing and mixing into another culture and becoming more Americanized. And it'll be like a lot of fast foods... Being Mexican-Guatemalan-American, I want to eat the food that comes from the countries that my parents come from. It allows me to connect with them and my culture more. I feel like now there's just not enough to connect me back there. So I just feel American. [Jennifer]

Another second-generation American student, Daniel, noted the importance of combatting "Americanization" to uphold his identity, 
It's like you either let [acculturation] take over, and you become Americanized, or you have to push back and like create a space within yourself. [Daniel]

These quotes reveal the importance that cultural food security has on second-generation American students' cultural and ethnic identity and the role that preparing, sharing, and consuming cultural foods have in this relationship. The preparation, sharing, and consumption of cultural foods are vital to prevent identity loss as it allows them to connect back to their culture and uphold cultural traditions. When cultural food insecurity prevented foodways practices and students felt identity loss, some students fought back against "Americanization" to uphold their identity.

\subsubsection{Foodways' influence on physical, mental, and emotional well-being [pathway 2C]}

While sharing cultural foods was a way for students to connect with their family and peers, it was also an incredibly vulnerable process. Students often feared that people would reject their cultural foods, which, unfortunately, sometimes occurred. One student recalled a story of when she shared her cultural foods with some acquaintances, and they rejected her cultural foods.

I've hung out with people who don't identify how I identify in any way. There was this one time we got together with a group of friends who were not like me at all from all different cultures. I went to this party, and they decided they wanted some [Mexican] hot chocolate. And I make it, and it wasn't what they had expected. So then, when they tried it out, there was a lot of people who didn't like it and rejected it in the meanest of ways, and it made me feel really sad. Because I like it, but they don't, so I feel like I can't really connect with them. [Jennifer]

More typically, second-generation Americans revealed that they associated eating cultural foods with positive feelings. Students' words to describe their well-being were happy, safe, warm, comforted, relaxed, mentally clear, and gave them a boost of morale. Sharing foods with others also produced positive emotions and was seen as a way of showing love and care.

Sharing foods makes me feel great and wonderful. I don't know where I learned it from, but I always believed in sharing what makes you happy, right. So for me, food makes me very happy, so I like to share foods. I feel very happy and very excited to share my foods. Yeah, it is a little bit of warmth. A very blissful feeling,
I guess. It's a little bit of a calming sense of meaning. [Cloud]

Eating cultural foods during high-stress times, such as during exam weeks, created a calming effect and eased anxiety for these students. Jasmine was one student who expressed this sentiment, "when it's a stressful day at school or work, I just eat Filipino food, and it's like a weight is taken off of me." Students craved traditional foods during times of stress and anxiety. These comfort foods were typically served to them as children by their parents or grandparents to make them feel better. Jasmine went on to say, "my grandma told me that pancit ${ }^{3}$ represents good well-being. Usually, if I had a bad day or I was sick, my mom would make me pancit." Many students expressed that familiarity with the foods and their association with comfort made them feel safe, secure, and relaxed. Without these foods, students had to find unique ways to cope with their stress and anxiety. Jasmine continued,

Um, so coming into college, when I was overwhelmed, I really wanted to eat something that I was used to. I really did want Filipino food. 'Cause if I was having a bad day, or if I was upset, I used to eat Filipino food and then coming into college, I couldn't do that, so I would have to find a different way to cope.

Not being able to prepare, share, or consume cultural foods that contributed to upholding their identity negatively impacted the students' well-being [pathway 3]. Students mentioned feelings of disconnect from their culture and identity, leading to sadness, depression, anxiety, and loneliness.

Not being able to do those recipes, for example, that my grandmother made, that she passed on to my mother, that passed down to myself. I'm not able to do that and maintain my identity. So, it definitely makes me sad. As far as physical, I think [it is] linked with my depression. I think probably just tired and not just wanting to kind of get up [out of bed]. [Joanna]

Angel similarly explained, "not being able to cook my cultural foods is kind of disappointing and sad. It impacts both my identity and well-being. It adds onto my depression. Being able to access those foods connects me back to my family."

Cultural food insecurity increases the difficulty of preparing, sharing, and consuming cultural foods, which students mentioned made them feel culturally disconnected, isolated, and alone, as highlighted here by Chelsey and Jessie.

\footnotetext{
${ }^{3}$ Pancit is a Filipino noodle dish that contains meat and vegetables. It is usually consumed on holidays or for big celebrations.
} 
Not being able to make and eat my Filipino food makes me feel alone, and uh, I already feel disconnected. I'm not fluent in the language. It is like another disconnect. I don't feel connected back to my culture. Being in grad school and being away from family, there's such a disconnect that I feel. I'm not really practicing my culture. [Chelsey]

I feel really left out and really isolated up here [in Reno]. I don't have family up here to exchange my cultural foods with, and the ingredients I need up here aren't often available. I definitely feel alienated. [Jessie]

Additionally, the students mentioned that in and outside of the dorms were foreign to them, and it was hard for them to adjust to eating "American" foods.

Not having my cultural foods sucked. I remember being like, 'the food here [in Reno] doesn't taste very good,' and that was my big issue. I feel like it was really difficult. I will admit that I tend to eat a lot when I get stressed out, and I was eating a lot of bad 'American foods' or not healthy foods, rather than food that was conducive to a healthy adult. [Aaron]

Many students felt that eating traditional "American foods" was cheating on their culture. Second-generation American students also cited digestion issues, mental fog, and sluggishness when switching to "American foods." Others mentioned that overly processed and high-fat foods caused them to gain weight.

Everything I ate at home was homemade and fresh. When I moved here [to Reno], I feel like I gained a lot of weight. Everything here is processed, and I didn't like that - how my body felt. Like my body felt slow. Also, everything on campus is very American. It'd be nice to get away from that and just be somewhere that I'm more familiar with, and that makes me and my body feel a lot happier. [Alice]

These quotes highlight the importance of foodways in identity maintenance and well-being in second-generation American students and reveal how interconnected these three components are. Foodways acted as a cultural transmission to practice and express their cultural identity, making them feel connected with their culture. The students mentioned that the act of conducting foodways, as well as feeling culturally connected, improved their well-being.

\subsection{Challenges in achieving cultural food security}

Most of the students mentioned that there were often barriers that lead to diminished or complete cultural food insecurity, such as the inability to access cultural foods (e.g., transportation, finances), the unavailability of cultural foods, diminished income, and the absence of cooking resources (e.g., stove, utensils). When many of the students moved to Reno, they were disappointed in the availability and accessibility of cultural foods. Jasmine explained the difficulty of finding Filipino ingredients in Reno,

It's hard even getting any ingredients for Filipino food, and you have to really have to search out for them. 'Cause like some, some dishes they do just have like simple ingredients, but like a lot of them do need specific Filipino ingredients and like, there are Asian markets here in Reno, but most do not carry the ingredients that I do need, so often I can't get the ingredients I need to remotely make a Filipino meal. [Jasmine]

In addition to cultural foods being unavailable, they were typically expensive, and students had to travel to multiple stores to get the ingredients they needed for just one meal, which was often timely for the students. As Jennifer indicated,

It's often time and money that are the issue. Like, do I have enough to get the foods? Because my foods are made with natural ingredients and most of the traditional ingredients are expensive. Also, because I have to go find them all over Reno. It takes so much time and if I don't have a lot of time, I'll just go buy fast food. [Jennifer]

However, when cultural foods were available and accessible, many students thought the quality and authenticity was lacking.

And for Chinese New Year's, we would eat like a lot of seafood and roast meat. And just, I feel like that's just hard to get a hold of here in Reno. And if you do, it's not really like fresh. It's like probably imported from another area and I don't know how long it's been in the market. So, it's hard to find good quality and like the authentic stuff in stores here. [Jessie]

Sarah explained how starkly different cultural food access was from Las Vegas to Reno,

I come from a place where I'm lucky enough to come from Las Vegas which has a whole Chinatown, and just having that was so amazing because they have a big nice clean market with like crawfish and like fresh chicken, and every spice you can think of, all the types of seaweed you need, all of the snacks, desserts, everything. Whereas like the Asian markets I've come to here 
in Reno have limited ingredients, are much smaller, hard to find, and are not getting by very well. [Sarah]

Many students would bring traditional foods back with them after visiting their family back home to combat most of these barriers. However, Jessie went on to explain that this was not always the best solution,

When I go home, I like to bring actual ingredients from my home in Vegas down here and try to make it. But even that is kind of inconvenient cause you don't, and you can't get to make something whenever you want. It's like you kind of have to plan it out. And I don't get to go home that often. [Jessie]

These quotes highlight the barriers the second-generation American students face in achieving cultural food security and one method many use to overcome these barriers. Cultural food insecurity further inhibits preparing, sharing, and consuming cultural foods [pathway 1A] and diminishes second-generation American students' well-being [pathway 1B]. Identifying additional solutions to overcome these barriers will further help maintain second-generation American students' identity and wellbeing [pathways 1B, 2A, 2B, 2C, \& 3].

\section{Discussion}

The study's purpose was to theorize how cultural food security influenced identity and well-being in second-generation American university students. This paper creates an entryway into the theorized role that cultural food security plays in identity maintenance and well-being in the second-generation U.S. American students. Cultural food security played a crucial role in the second-generation American students' identity creation and preservation, which enabled them to create and maintain their own food culture cultural foods (Cardona 2004; Jamal 1996). Second-generation American university students, in particular, experience additional barriers while attending college, which leads to higher stress levels and adverse well-being outcomes (Finch et al. 2001; Finch and Vega 2003; Flores et al. 2008; Lee et al. 2004).

Previous studies (Gabaccia 1998) found that adjusting to an unfamiliar environment can be stressful for non-secondgeneration American and international college students; however, our study found that second-generation Americans had added feelings of culture shock; a term often reserved for international students and travelers (Brown and Holloway 2008; Constantine et al. 2005; Ineson et al. 2006; Pantelidou and Craig 2006). This supports the idea that second-generation Americans can be considered academic sojourners as students can move from areas of the country with a large cultural or ethnic group to another region for college with a culturally dissimilar population. As these students are also staying temporarily, the term sojourner can also be applied.

When second-generation Americans off to college and disperse from their families, it is up to them to find a way to uphold these cultural practices. On top of this pressure, students are also struggling with their self-identity as they move from late adolescence into young adulthood, while also becoming disoriented in an unfamiliar environment without their foodways and cultural ties. Thus, this is a tumultuous time for second-generation Americans, in which they are experiencing a significant amount of stress. Universities may thwart access and availability stressors by developing campus organizations to identify their cultural food needs and secure food and monetary donors to supplement the food pantry with cultural food staples. These organizations could further develop a grocer and restaurant directory with transportation information for each.

Cultural foods are potentially a remedial solution to alleviate cultural shock and acculturative stress in second-generation Americans. Sharing cultural foods was critical for the students to reinforce a sense of communality. Universities should also create cultural communities to foster connections and bonds with other cultural group members to alleviate culture shock symptoms (Pantelidou and Craig 2006). Similar to other studies, foodways were the juncture of food and culture, in which cultural members came together to consume traditional foods and participate in cultural practices and rituals whereby they also commemorated and strengthened their cultural ties and identity [pathway 2A] (Camp 1989; James 2004; Koc and Welsh 2001; Noriza et al. 2012; Parraga 1990; Peñaloza 1994; Steinberg 2012). During these food events, cultural members bonded over commonalities such as language, food, dance, and music. Unfortunately, the students in this study mentioned that the campus's cultural groups were not as robust as they wished and did not provide substantial support in how they needed due to the small university size. Universities encountering similar struggles may create a broader cultural community to allow students to provide support for struggles specific to secondgeneration American students.

Future research can identify ways to reduce academic and cultural stress in second-generation American students to ensure academic success and identity maintenance. Qualitative interviews with second-generation American university students could identify the best practices for reducing the academic transition challenges to allow university leaders and policymakers to assist second-generation American students more efficiently. While this study adds to the limited research examining the effects of cultural food security on identity and well-being, additional research is needed to better understand these concepts' interconnection and operationalization in other cultural and ethnic groups. Overall the study's findings add support to the conceptual framework (Fig. 1), which helps add clarity to the deeply woven network of cultural food security, foodways, identity, and well-being. 


\subsection{Limitations}

Our exploratory findings should be considered in light of a few potential limitations. First, the student participants were a convenience sample based on those who clicked on the screener survey link provided in the dissemination email. These findings may not represent other students' experiences or the entire second-generation American student body at UNR or other universities. While our sample size is consistent with other qualitative investigations, the generalizability of the findings to other second-generation American students is cautioned as not all cultural and ethnic groups at UNR were included in this study. Thus, it is essential to note that the conceptual framework's relationships may exist differently in other populations as other components may exist in the conceptual framework. The pathways may exist in a different direction based on cultural norms and values.

\subsection{Conclusion}

Despite these limitations, this study has helped add to the understanding of the second-generation American college student experience and further outline the relationship between cultural food security, foodways, acculturation, identity, and well-being. The increase in secondgeneration Americans at universities (Arbeit et al. 2016) necessitates examining methods to improve this population's health and well-being. The study results have important implications for universities to improve secondgeneration Americans' well-being, such as developing mandatory policies to increase cultural foods' accessibility and create cultural communities amongst the student body. Increasing awareness about the cultural adjustments that second-generation Americans face can lead to second-generation American-tailored programs to diminish cultural strain. Further research should use qualitative interviews with second-generation Americans to explore how the university environment can influence academic transition for second-generation American students to reduce cultural, social, and cognitive challenges' that inherently exist in academic transition.

Supplementary Information The online version contains supplementary material available at https://doi.org/10.1007/s12571-020-01140-w.

Acknowledgments The authors thank the volunteers who participated in this study and the University of Nevada, Reno faculty who helped disseminate the project information. The authors would also like to thank Cathryn Seibel, Sahand Dehghani, Nana-Adowa Boateng, Cameron Arai, and Liara Marie Santos for their help in transcribing the audio files.

\section{Compliance with ethical standards}

Conflicts of interest/competing interests The authors declare that they have no conflict of interest.

Ethics approval This study was approved by the University of Nevada, Reno's Institutional Review Board.

Consent to participate Written informed consent was obtained from the students before the interview.

Consent for publication The participants consented to the submission of the data to the journal.

\section{References}

Alonso, E. B., Cockx, L., \& Swinnen, J. (2018). Culture and food security. Global Food Security, 17, 113-127. https://doi.org/10.1016/j. gfs.2018.02.002.

Angel, J. L., Buckley, C. J., \& Sakamoto, A. (2001). Duration or disadvantage? Exploring nativity, ethnicity, and health in midlife. The Journals of Gerontology Series B: Psychological Sciences and Social Sciences, 56(5), S275-S284.

Arbeit, C. A., Staklis, S., \& RTI International. (2016). New American undergraduates: Enrollment trends and age at arrival of immigrant and second-generation students. (statistics in brief NCES 2017414). Institute of Education Sciences. https://nces.ed.gov/ pubs2017/2017414.pdf

Beoku-Betts, J. A. (1995). We got our way of cooking things: Women, food, and preservation of cultural identity among the Gullah. Gender \& Society, 9(5), 535-555.

Brady, S. E., \& Stevens, M. C. (2019). Is immigration a culture? A qualitative approach to exploring immigrant student experiences within the United States. Translational Issues in Psychological Science, 5(1), 17-28.

Braun, V., \& Clarke, V. (2006). Using thematic analysis in psychology. Qualitative Research in Psychology, 3(2), 77-101. https://doi.org/ 10.1191/1478088706qp063oa.

Brown, L. (2008). The incidence of study-related stress in international students in the initial stage of the international sojourn. Journal of Studies in International Education, 12(1), 5-28.

Brown, L., \& Holloway, I. (2008). The initial stage of the international sojourn: Excitement or culture shock? British Journal of Guidance \& Counselling, 36(1), 33-49.

Burnett-Zeigler, I., Bohnert, K. M., \& Ilgen, M. A. (2013). Ethnic identity, acculturation and the prevalence of lifetime psychiatric disorders among black, Hispanic, and Asian adults in the US. Journal of Psychiatric Research, 47(1), 56-63.

Camp, C. (1989). American foodways: What, when, why and how we eat in America (first). August House.

Cardona, E. T. C. (2004). Re-encountering Cuban tastes in Australia. The Australian Journal of Anthropology, 15(1), 40-53.

Chang, W.-W. (2009). Schema adjustment in cross-cultural encounters: A study of expatriate international aid service workers. International Journal of Intercultural Relations, 33(1), 57-68.

Constantine, M. G., Anderson, G. M., Berkel, L. A., Caldwell, L. D., \& Utsey, S. O. (2005). Examining the cultural adjustment experiences of African international college students: A qualitative analysis. Journal of Counseling Psychology, 52(1), 57-66.

Coveney, J., \& Bunton, R. (2003). In pursuit of the study of pleasure: Implications for health research and practice. Health, 7(2), 161-179. https://doi.org/10.1177/1363459303007002873. 
Creswell, J. W., \& Creswell, J. D. (2018). Research design: Qualitative, quantitative, and mixed methods approaches (5th ed.). SAGE Publications, INC.

Damman, S., Eide, W. B., \& Kuhnlein, H. V. (2008). Indigenous peoples' nutrition transition in a right to food perspective. Food Policy, 33(2), $135-155$.

Daponte, B. O., \& Bade, S. L. (2000). The evolution, cost, and operation of the private food assistance network. Institute for Research on Poverty, University of Wisconsin-Madison.

Eaton, T. W. (2006). Path to the professoriate for high-achieving, firstgeneration college students (Doctoral Dissertation). The University of Oklahoma. https://shareok.org/handle/11244/1067.

El Zein, A., Shelnutt, K., Colby, S., Olfert, M., Kattelmann, K., Brown, O., Kidd, T., Horacek, T., White, A., \& Zhou, W. (2017). Sociodemographic correlates and predictors of food insecurity among first year college students. Journal of the Academy of Nutrition and Dietetics, 117(10), A146.

Feeley-Harnik, G. (1995). Religion and food: An anthropological perspective. Journal of the American Academy of Religion, 63(3), $565-582$.

Fieldhouse, P. (1995). Social functions of food. In Food and Nutrition: Customs and Culture (pp. 78-105). Springer.

Finch, B. K., Hummer, R. A., Kol, B., \& Vega, W. A. (2001). The role of discrimination and acculturative stress in the physical health of Mexican-origin adults. Hispanic Journal of Behavioral Sciences, 23(4), 399-429.

Finch, B. K., \& Vega, W. A. (2003). Acculturation stress, social support, and self-rated health among Latinos in California. Journal of Immigrant Health, 5(3), 109-117.

Fisher, S. (1994). Stress in academic life: The mental assembly line. Open University Press.

Flores, E., Tschann, J. M., Dimas, J. M., Bachen, E. A., Pasch, L. A., \& de Groat, C. L. (2008). Perceived discrimination, perceived stress, and mental and physical health among Mexican-origin adults. Hispanic Journal of Behavioral Sciences, 30(4), 401-424.

Gabaccia, D. R. (1998). Immigration, isolation, and industry. In We Are What We Eat (p. 54). Harvard University press.

Gabaccia, D. R. (2009). We are what we eat: Ethnic food and the making of Americans. Harvard University Press.

Gaines, A., Robb, C. A., Knol, L. L., \& Sickler, S. (2014). Examining the role of financial factors, resources and skills in predicting food security status among college students. International Journal of Consumer Studies, 38(4), 374-384. https://doi.org/10.1111/ijcs. 12110.

Glaser, B. G., \& Strauss, A. L. (1967). The discovery of grounded theory: Strategies for qualitative research. Aldine.

Gray-Little, B., \& Hafdahl, A. R. (2000). Factors influencing racial comparisons of self-esteem: A quantitative review. Psychological Bulletin, 126(1), 26-54.

Herakova, L., \& Cooks, L. (2017). Hands in the dough: Bread and/as a pedagogy of performative remembering. Text and Performance Quarterly, 37(3-4), 239-256.

Ineson, E., Lyons, A., \& Branston, C. (2006). Cross cultural change, adjustment and culture shock: UK to USA. Tourism (Zagreb), 54(4), 355-365.

Jamal, A. (1996). Acculturation: The symbolism of ethnic eating among contemporary British consumers. British Food Journal., 98, 12-26.

James, D. (2004). Factors influencing food choices, dietary intake, and nutrition-related attitudes among African Americans: Application of a culturally sensitive model. Ethnicity \& Health, 9(4), 349-367. https://doi.org/10.1080/1355785042000285375.

Jung, E., Hecht, M. L., \& Wadsworth, B. C. (2007). The role of identity in international students' psychological well-being in the United States: A model of depression level, identity gaps, discrimination, and acculturation. International Journal of Intercultural Relations, 31(5), 605-624. https://doi.org/10.1016/j.ijintrel.2007.04.001.
Kammer, J. (2015). The hart-Celler immigration act of 1965. Center for Immigration Studies. https://cis.org/Report/HartCellerImmigration-Act-1965

Kim, Y. Y. (2001). Becoming intercultural: An integrative theory of communication and cross-cultural adaptation. Sage.

Kittler, P. G., Sucher, K. P., \& Nelms, M. (2011). Food and culture. Cengage Learning.

Koc, M., \& Welsh, J. (2001). Food, foodways and immigrant experience. Toronto: Centre for Studies in Food Security, 2, 46-48.

Lee, J.-S., Koeske, G. F., \& Sales, E. (2004). Social support buffering of acculturative stress: A study of mental health symptoms among Korean international students. International Journal of Intercultural Relations, 28(5), 399-414.

Liebkind, K., Jasinskaja-Lahti, I., \& Solheim, E. (2004). Cultural identity, perceived discrimination, and parental support as determinants of immigrants' school adjustments: Vietnamese youth in Finland. Journal of Adolescent Research, 19(6), 635-656.

Locher, J. L., Yoels, W. C., Maurer, D., \& Van Ells, J. (2005). Comfort foods: An exploratory journey into the social and emotional significance of food. Food \& Foodways, 13(4), 273-297.

Lum, C. M. K., \& de Ferrière le Vayer, M. (2016). Urban foodways and communication: ethnographic studies in intangible cultural food heritages around the world. Rowman \& Littlefield Publishers.

Mintz, S. W., \& Du Bois, C. M. (2002). The anthropology of food and eating. Annual Review of Anthropology, 31(1), 99-119.

Moffat, T., Mohammed, C., \& Newbold, K. (2017). Cultural dimensions of food insecurity among immigrants and refugees. Human Organization, 76(1), 15-27. https://doi.org/10.17730/0018-7259. 76.1.15.

Morales, E. E. (2012). Navigating new worlds: A real-time look at how successful and non-successful first-generation college students negotiate their first semesters. International Journal of Higher Education, 1(1), 90-101.

Muñoz, R. M. (2012). Low income, first generation community college students: Reflections on their success and their motivations (Doctoral Dissertation). Oklahoma State University.

Noriza, I., Zahari, M. M., Shazali, M., Rosmaliza, M., \& Hannita, S. (2012). Acculturation, foodways and Malaysian food identity. Current Issues in Hospitality and Tourism Research and Innovations, 359-363.

Osella, C., \& Osella, F. (2008). Food, memory, community: Kerala as both 'Indian Ocean'zone and as agricultural homeland. South Asia: Journal of South Asian Studies, 31(1), 170-198.

Outten, H. R., Schmitt, M. T., Garcia, D. M., \& Branscombe, N. R. (2008). Coping options: Missing links between minority group identification and psychological well-being. Applied Psychology, 58(1), 146-170.

Pantelidou, S., \& Craig, T. K. (2006). Culture shock and social support. Social Psychiatry and Psychiatric Epidemiology, 41(10), 777-781.

Parraga, I. M. (1990). Determinants of food consumption. Journal of the American Dietetic Association, 90(5), 661-663.

Payne-Sturges, D. C., Tjaden, A., Caldeira, K. M., Vincent, K. B., \& Arria, A. M. (2018). Student hunger on campus: Food insecurity among college students and implications for academic institutions. American Journal of Health Promotion, 32(2), 349-354.

Peñaloza, L. (1994). Atravesando fronteras/border crossings: A critical ethnographic exploration of the consumer acculturation of Mexican immigrants. Journal of Consumer Research, 21(1), 32-54.

Pew Research Center. (2015). Modern Immigration Wave Brings 59 Million to U.S., Driving Population Growth and Change Through 2065. https://www.pewresearch.org/hispanic/chart/first-andsecond-generation-share-of-the-population-1900-2018/

Pew Research Center. (2020). First- and second-generation share of the population, 1900-2018. https://www.pewresearch.org/hispanic/ chart/first-and-second-generation-share-of-the-population-19002018/ 
Phinney, J. S., Cantu, C. L., \& Kurtz, D. A. (1997). Ethnic and American identity as predictors of self-esteem among African American, Latino, and White adolescents. Journal of Youth and Adolescence, 26(2), 165-185.

Power, E. M. (2008). Conceptualizing food security for aboriginal people in Canada. Canadian Journal of Public Health, 99(2), 95-97.

QSR International Pty Ltd. (2018). NVivo (Version 12) [Computer software]. https://www.qsrinternational.com/nvivo-qualitative-dataanalysis-software/home

Qualtrics (2020). Qualtrics. https://www.qualtrics.com

Rabikowska, M. (2010). The ritualisation of food, home and national identity among polish migrants in London. Social Identities, 16(3), 377-398.

Roberts, R. E., Phinney, J. S., Masse, L. C., Chen, Y. R., Roberts, C. R., \& Romero, A. (1999). The structure of ethnic identity of young adolescents from diverse ethnocultural groups. The Journal of Early Adolescence, 19(3), 301-322.

Ruiz, A. S. (1990). Ethnic identity: Crisis and resolution. Journal of Multicultural Counseling and Development, 18(1), 29-40.

Ryff, C. D., Keyes, C. L., \& Hughes, D. L. (2003). Status inequalities, perceived discrimination, and eudaimonic well-being: Do the challenges of minority life hone purpose and growth? Journal of Health and Social Behavior, 275-291.

Sanou, D., O’Reilly, E., Ngnie-Teta, I., Batal, M., Mondain, N., Andrew, C., Newbold, B. K., \& Bourgeault, I. L. (2014). Acculturation and nutritional health of immigrants in Canada: A scoping review. Journal of Immigrant and Minority Health, 16(1), 24-34.

Schackmuth, K. (2012). An exploration of the experiences of firstgeneration college students in Lasallian higher education (Doctoral Dissertation). Loyola University Chicago.

Schermuly, A. C., \& Forbes-Mewett, H. (2016). Food, identity and belonging: A case study of south African-Australians. British Food Journal, 118(10), 2434-2443.

Schwartz, S. J., Unger, J. B., Zamboanga, B. L., \& Szapocznik, J. (2010). Rethinking the concept of acculturation: Implications for theory and research. American Psychologist, 65(4), 237-251.

Schwartz, S. J., Waterman, A. S., Umaña-Taylor, A. J., Lee, R. M., Kim, S. Y., Vazsonyi, A. T., Huynh, Q., Whitbourne, S. K., Park, I. J., \& Hudson, M. (2013). Acculturation and well-being among college students from immigrant families. Journal of Clinical Psychology, 69(4), 298-318.

Schwartz, S. J., Weisskirch, R. S., Zamboanga, B. L., Castillo, L. G., Ham, L. S., Huynh, Q.-L., Park, I. J., Donovan, R., Kim, S. Y., \& Vernon, M. (2011). Dimensions of acculturation: Associations with health risk behaviors among college students from immigrant families. Journal of Counseling Psychology, 58(1), 27-41.

Skulley, K. L. (2004). Latinas first-generation college students' perceptions of their college experiences (Doctoral Dissertation). University of Northern Colorado.

Sodowsky, G. R., \& Wai Ming Lai, E. (1997). Asian immigrant variables and structural models of cross-cultural distress. In A. Booth, A. C. Crouter, \& N. S. Landale (Eds.), Immigration and the family: Research and policy on U.S. immigrants (pp. 211-234). Lawrence Erlbaum Associates, Inc..

Steinberg, A. (2012). What we talk about when we talk about food: Using food to teach history at the tenement museum. The Public Historian, 34(2), 79-89.

The Collaborative Institutional Training Initiative. (2020). SocialBehavioral-Educational (SBE) Basic. https://about.citiprogram.org/ en/course/human-subjects-research-2/

Trainer, S., Hardin, J., SturtzSreetharan, C., \& Brewis, A. (2020). Worrynostalgia: Anxieties around the fading of local cuisines and Foodways. Gastronomica, 20(2), 67-78.

Tsai, J. L., Ying, Y.-W., \& Lee, P. A. (2001). Cultural predictors of selfesteem: A study of Chinese American female and male young adults. Cultural Diversity and Ethnic Minority Psychology, 7(3), 284-297.

Umaña-Taylor, A. J., Diversi, M., \& Fine, M. A. (2002). Ethnic identity and self-esteem of Latino adolescents: Distinctions among the Latino populations. Journal of Adolescent Research, 17(3), 303327.

US Census Bureau. (2019a). Quick Facts—Las Vegas, Nevada. https:// www.census.gov/quickfacts/lasvegascitynevada

US Census Bureau. (2019b). Quick Facts—Reno, Nevada. https://www. census.gov/quickfacts/renocitynevada

US Department of Agriculture (2012). U.S. Household Food Security Survey Module: Six-Item Short Form Economic Research Service, USDA. https://www.ers.usda.gov/media/8282/short2012.pdf

Utsey, S. O., Chae, M. H., Brown, C. F., \& Kelly, D. (2002). Effect of ethnic group membership on ethnic identity, race-related stress, and quality of life. Cultural Diversity and Ethnic Minority Psychology, 8(4), 366-377.

Vallianatos, H., \& Raine, K. (2008). Consuming food and constructing identities among Arabic and south Asian immigrant women. Food, Culture \& Society, 11(3), 355-373. https://doi.org/10.2752/ 175174408 X347900.

Ward, C. A., Bochner, S., \& Furnham, A. (2001). The psychology of culture shock (2nd ed.). Routledge.

Weller, D. L., \& Turkon, D. (2015). Contextualizing the immigrant experience: The role of food and foodways in identity maintenance and formation for first-and second-generation Latinos in Ithaca, New York. Ecology of Food and Nutrition, 54(1), 57-73.

Williams-Forson, P. (2014). "I haven't eaten if I don't have my soup and fufu": Cultural preservation through food and foodways among Ghanaian migrants in the United States. Africa Today, 61(1), 69-87.

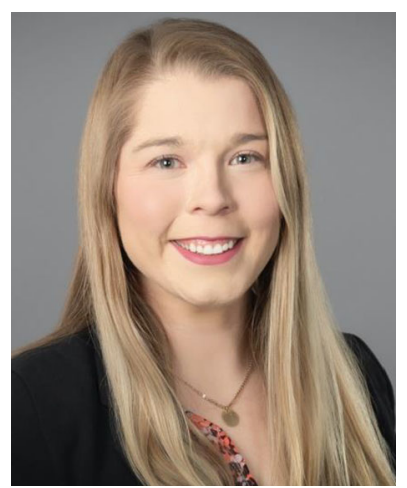

Kathrine E. Wright recently earned her Ph.D. in Public Health from the University of Nevada, Reno in August 2020. Her research focuses on food insecurity and food inequity and the role these two constructs have in creating health disparities. Wright utilizes a CBPR approach to address cultural level factors that may alleviate food insecurity and poor health outcomes associated with food insecurity. She is currently using anthropological theories and concepts through a public health lens to understand further how cultural food security impacts cultural identity and well-being. She believes that a multi-disciplinary approach that combines public health and anthropology is needed to tackle particular food insecurity aspects not widely addressed. 


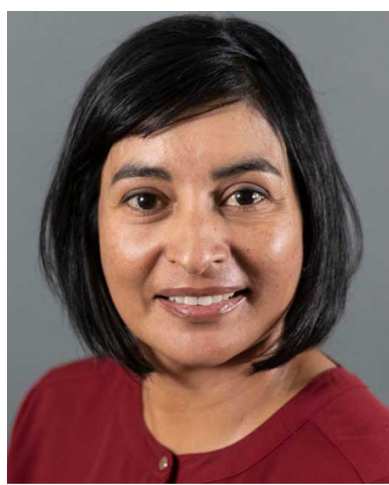

Julie E. Lucero using mixed methods and Community Based Participatory Research (CBPR), Julie Lucero's research is centered on identifying modifiable social determinants to reduce the impact of health inequities within marginalized populations. Lucero has been involved with CBPR projects in collaboration with American Indian, Hispanic, and LGBT communities. These projects examined factors associated with substance abuse, mental health, positive youth development, and service utilization. Her current research explores the role of trust in promoting effective processes and outcomes in community-academic partnerships. In previous research, we found trust at the beginning of research partnerships associated with participation, power relations, sustainability, and overall research outcomes. Trust, Governance, and Culture were found to be cross-cutting themes (pillars) associated with various outcomes throughout the partnering and research process. She currently collaborates with the National Congress of American Indians Policy Research Center to develop a toolkit focused on the three pillars.

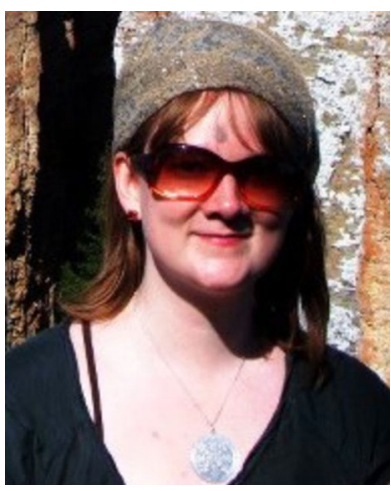

Jenanne K. Ferguson current research deals with the maintenance and transmission of the Sakha (Yakut) language in northeastern Siberia, Russia, through the lens of mobility by and through language. Her dissertation works dealt with speaking Sakha among Sakha-Russian bilinguals living in urban and rural regions and the language ideologies shaping their language choices and practices. Ongoing and future work deals with the revitalization and transformation of Sakha oral literary genres and the local creation of new online spaces (e.g., social networking, SMS, Wikipedia) for Sakha language transmission and usage, as well as a project comparing the politics and aesthetics of indigenous storytelling in Canada and Russia. She also has worked on questions and themes (language in education; language in the visual spheres) with Canadian indigenous languages in the past. She welcomes inquiries from students interested in similar themes and approaches to language, regardless of geographic area.

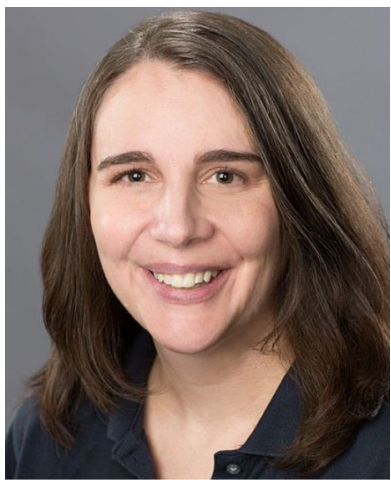

Michelle L. Granner research focuses on physical activity, sedentary, and nutrition behaviors. Her research includes understanding and promoting health behaviors, the influence of the built environment on behavior, and community approaches. Other research interests include women's health, health communication, mindfulness, evaluation, and community-based participatory research. She is currently a co-investigator on a USDAfunded grant to evaluate a national media campaign promoting breastfeeding among women who participate in the WIC program.

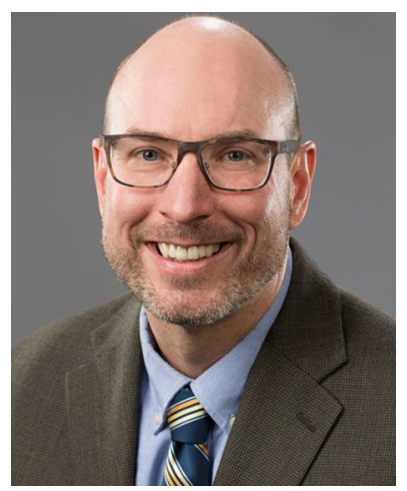

Paul G. Devereux is an Associate Professor of Social Behavioral Health at the School of Community Health Sciences, University of Nevada, Reno. He holds an MPH in community health education from San José State University and a Ph.D. in Social Psychology from the University of Nevada Reno. Dr. Devereux's scholarship explores the social and behavioral determinants of health and well-being. Specific research topics include evaluating community-based approaches to colorectal cancer screening interventions, perceptions of cancer screening, social support in diverse populations such as people with disabilities, parenting adolescents, and U.S. judges. He also studies emotion regulation in older adults. His research has been funded by NIH, CDC, HRSA, and private foundations. Dr. Devereux is the former President of the Nevada Public Health Association and was named Nevada Public Health Leader of the Year in 2005.

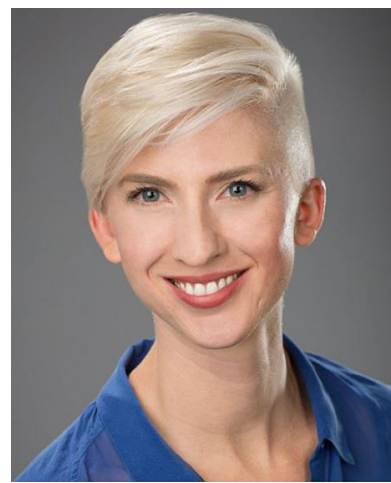

Jennifer L. Pearson assistant professor of health administration and policy at the University of Nevada, Reno School of Community Health Sciences, recently published a study about the policies concerning the use of e-cigarettes in Tobacco Control. Dr. Pearson and coauthors recommend specific focal points that may serve as a starting point for further evaluations of the effects of e-cigarette use. Dr. Pearson's study recognizes the transient nature of e-cigarettes and, therefore, the transient nature of public policy associated with them. Dr. Pearson's research primarily focuses on the adverse health outcomes associated with tobacco use in addition to the regulation of tobacco products. Her research interests include tobacco regulatory science- specifically, e-cigarettes and tobacco products claiming to be "natural," "additive-free," or "organic."

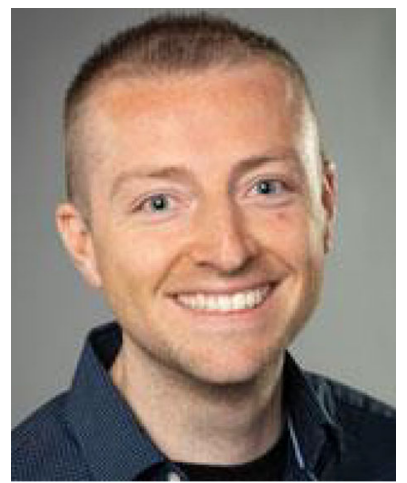

Eric Crosbie Eric Crosbie is a political scientist who examines commercial determinants of health and public health policy. His research focuses on noncommunicable diseases (NCDs) and examines how commercial industries like tobacco and food and beverage industries are a vital driver of the NCD epidemic and how they influence NCD regulations. Dr. Crosbie's research is local in analyzing smoke-free environments and sugar-sweetened beverage taxation regulations in the U.S. and global in examining tobacco and nutrition packaging and labeling policies and the impact of trade on health. Dr. Crosbie has local and international experience collaborating with health organizations and 
health advocates to educate and disseminate academic research findings to policymakers, including publishing research in Spanish to reach wider audiences. Overall his research is multi-disciplinary, combining political science, public health, political science, international relations, economics, law, and business to examine public health policy both locally and globally. 